\title{
Modulation of adhesion and growth of colon and pancreatic cancer cells by the histone deacetylase inhibitor valproic acid
}

\author{
JON JONES*, WASSILIOS BENTAS, ROMAN A. BLAHETA, JASMINA MAKAREVIC, \\ LUKASZ HUDAK, STEFFEN WEDEL, MICHAEL PROBST, DIETGER JONAS and EVA JUENGEL \\ Klinik für Urologie und Kinderurologie, Zentrum der Chirurgie, \\ Johann Wolfgang Goethe-Universität; Frankfurt am Main, Germany
}

Received March 21, 2008; Accepted May 7, 2008

DOI: 10.3892/ijmm_00000022

\begin{abstract}
Histone deacetylase (HDAC) inhibitors belong to a promising class of antineoplastic agents which affect tumor growth, differentiation and invasion. The effects of the HDAC inhibitor valproic acid (VPA) were tested in vitro on preclinical colon and pancreatic cancer models. Human colon adenocarcinoma HT-29 and pancreatic carcinoma DanG cells were treated with $1 \mathrm{mM}$ VPA for different time periods during cell proliferation MTT assays, and to evaluate the tumor cell adhesion to endothelial cell monolayers. Alterations of $\beta 1$ integrin subunits $(\alpha 1-6)$ were analyzed by flow cytometry and RT-PCR. VPA significantly caused growth arrest in tumor cells and prevented tumor cell attachment to the endothelium. HT-29 cell adhesion was blocked to a higher extent than the adhesion of DanG cells. VPA modified membranous integrin B1 expression, quantity and quality (up- or down-regulation) which depended on the tumor type investigated. Furthermore, VPA diminished integrin coding mRNA in HT-29 but not in DanG cells. We conclude that VPA shifts the integrin $B 1$ subunit balance from a 'pathological' towards a 'physiological' expression pattern leading to reduced tumor growth and invasion. Further study is required to elucidate the molecular background of the post-transcriptional modifications of VPA in order to exploit the potential of this agent in the treatment of colon and pancreatic cancer.
\end{abstract}

\section{Introduction}

Among the multiple genetic and cytogenetic alterations which characterize human tumors, great emphasis has recently

Correspondence to: Dr Roman Blaheta, J.W. GoetheUniversitätsklinik, Klinik für Urologie und Kinderurologie, Interdisziplinäres Forschungs- und Laborgebäude, Chirurgische Forschung, Haus 25, Zi 204, Theodor-Stern-Kai 7, D-60590 Frankfurt am Main, Germany

E-mail: blaheta@em.uni-frankfurt.de

Key words: colon cancer, pancreatic cancer, histone deacetylase, valproic acid, integrins been given to epigenetic events, such as DNA methylation or histone acetylation. Alterations in histone acetyl transferase or histone deacetylase activity occur in numerous cancers and have prompted the search for pharmacological agents capable of inhibiting these enzymes. Histone deacetylase (HDAC) inhibitors seem to be specifically selective against tumor cells and show a very low toxicity.

Among the growing list of HDAC inhibitors, the branchedchain fatty acid valproic acid (VPA) has been shown to possess distinct HDAC inhibitory properties and to affect the growth and survival of a spectrum of both haematological and solid tumors in vitro and in vivo $(1,2)$. This is highly relevant since VPA is an established drug for the long-term therapy of epilepsy. It can be administered orally, negative side effects are rare, and it demonstrates expedient pharmacokinetic properties. Currently, the drug is in phase I trials $(3,4)$.

Only limited information is available on the activity of VPA against colon and pancreatic cancer. Therefore, the effects of VPA, applied for different time periods, on the proliferation and adhesion kinetics of pancreatic and colon tumor cell lines were evaluated. The expression pattern of integrin subtypes was also investigated, since receptors of the integrin family are known to be important mediators of tumor cell de-differentiation, tumor cell invasion and tumor cell proliferation (5).

\section{Materials and methods}

Cell cultures. Human colon adenocarcinoma HT-29 and pancreatic carcinoma DanG cells were derived from the tumor cell bank of the Johannes-Gutenberg University (Mainz, Germany). Tumor cells were grown and subcultured in RPMI-1640 medium (Gibco, Karlsruhe, Germany) supplemented with $10 \%$ fetal calf serum (FCS; Gibco), 100 IU/ $\mathrm{ml}$ penicillin and $100 \mu \mathrm{g} / \mathrm{ml}$ streptomycin (Gibco), glutamax-1 (Gibco) and $20 \mathrm{mM}$ HEPES buffer (Sigma, Steinheim, Germany) at $37^{\circ} \mathrm{C}$ in a humidified, $5 \% \mathrm{CO}_{2}$ incubator.

Endothelial cells (HUVECs) were isolated from human umbilical veins and harvested by enzymatic treatment with dispase (Sigma, Taufkirchen, Germany). HUVECs were grown in Medium 199 (Gibco), 10\% fetal calf serum (FCS; Gibco), $10 \%$ pooled human serum (Blood Bank of The German Red Cross, Frankfurt am Main, Germany), $20 \mu \mathrm{g} / \mathrm{ml}$ endothelial cell growth factor (Roche, Mannheim, Germany), 
$0.1 \%$ heparin (Roche), $100 \mathrm{ng} / \mathrm{ml}$ gentamycin (Gibco) and $20 \mathrm{mM}$ HEPES buffer. To control the purity of HUVEC cultures, cells were stained with fluorescein isothiocyanate (FITC)-labelled monoclonal antibody against Factor VIIIassociated antigen (Von Willebrand factor; clone F8/86; Dako, Hamburg, Germany) and analyzed microscopically or by FACscan (Becton Dickinson, Heidelberg, Germany; FL-1H (log) channel histogram analysis; $1 \times 10^{4}$ cells/scan). Cell cultures with a purity $>95 \%$ were serially passaged. Subcultures from passages 2-4 were selected for experimental use.

Tumor cell growth. Cell proliferation was assessed using the Cell Proliferation Kit I [MTT, 3-(4,5-dimethylthiazol-2-yl)2,5-diphenyltetrazolium bromide; Roche Diagnostics, Penzberg, Germany). HT-29 and DanG cells (100 $\mu 1$, $1 \times 10^{5}$ cells $/ \mathrm{ml}$ ) were seeded onto 96-well tissue culture plates and incubated as described above. After $24 \mathrm{~h}$, MTT $(0.5 \mathrm{mg} /$ $\mathrm{ml}$ ) was added for an additional $4 \mathrm{~h}$. Thereafter, cells were lysed in a solubilization solution containing 10\% SDS in $0.01 \mathrm{M} \mathrm{HCl}$. The plates were incubated overnight at $37^{\circ} \mathrm{C}$ in $5 \% \mathrm{CO}_{2}$. The absorbance at $570 \mathrm{~nm}$ was determined for each well using a microplate ELISA reader. Each experiment was conducted in triplicate. After subtracting the background absorbance, the results were expressed as the mean cell number.

Monolayer adhesion assay. HUVECs were transferred to 6well multiplates (Falcon Primaria; Becton Dickinson) in complete HUVEC-medium. When confluency was reached, $5 \times 10^{5}$ tumor cells/well were carefully added to the HUVEC monolayer for different time periods. Subsequently, nonadherent tumor cells were washed off using warmed $\left(37^{\circ} \mathrm{C}\right)$ phosphate-buffered saline (PBS). The adherent cells were fixed with $1 \%$ glutaraldehyde and counted in five different fields $\left(5 \times 0.25 \mathrm{~mm}^{2}\right)$ using a phase contrast microscope (x20 objective) to calculate the mean cellular adhesion rate.

Evaluation of integrin surface expression. Tumor cells were washed in blocking solution (PBS, $0.5 \% \mathrm{BSA}$ ) and then incubated for $60 \mathrm{~min}$ at $4^{\circ} \mathrm{C}$ with the FITC-conjugated monoclonal antibody anti- $\alpha 2 \beta 1$ (Becton Dickinson; clone AK-7), anti- $\alpha 4 \beta 1$ (Cymbus Biotechnology, Hofheim, Germany; clone HP2I1), anti- $\alpha 5 \beta 1$ (Cymbus Biotechnology; clone SAM-1), anti- $\alpha 631$ (Becton Dickinson; clone GOH3), or with the PE-conjugated monoclonal antibody anti- $\alpha 1 \beta 1$ (Becton Dickinson; clone SR84), or anti- $\alpha 3 \beta 1$ (Becton Dickinson; clone C3II1). Integrin expression of tumor cells was then measured using a FACscan (Becton Dickinson; FL-1H or FL-2H (log) channel histogram analysis; $1 \times 10^{4}$ cells/scan) and expressed as mean fluorescence units (MFU). A mouse IgG1-FITC was used as an isotype control for FITCconjugated antibodies. To evaluate the background staining of PE-conjugated antibodies, goat anti-mouse IgG-PE was used (all from Cymbus Biotechnology).

mRNA expression of $\beta 1$ integrins. mRNA expression of $\beta 1$ integrins was evaluated by reverse transcriptase-polymerase chain reaction (RT-PCR). Tumor cells were seeded in $25 \mathrm{~cm}^{2}$ culture flasks (Falcon Primaria, Becton Dickinson). Total
Table I. The sequences of the primers used for RT-PCR.

\begin{tabular}{llll}
\hline mRNA & \multicolumn{1}{c}{$\begin{array}{c}\text { Sense primer } \\
\text { sequence }\end{array}$} & \multicolumn{1}{c}{$\begin{array}{c}\text { Antisense primer } \\
\text { sequence }\end{array}$} & bp \\
\hline GAPDH & atcttccaggagcgagatcc & accactgacacgttggcagt & 509 \\
$\alpha 1 \beta 1$ & catgcgctcgtttggaa & cggccacatctcgggaccaga & 309 \\
$\alpha 2 \beta 1$ & gcatctcagaagtctgttgcc & cctgttgttaccttcagggag & 335 \\
$\alpha 3 \beta 1$ & tacgtgcgaggcaatgaccta & tttgggggtgcaggatgaagct & 306 \\
$\alpha 6 \beta 1$ & tggaggtacagttgttggcg & ctccgttaggttcagggagt & 253 \\
\hline
\end{tabular}

RNA was extracted by using the RNeasy Mini Kit (Qiagen, Hilden, Germany), and RNA samples were then treated with the RNase-free DNase Kit (Qiagen) for $15 \mathrm{~min}$ at $37^{\circ} \mathrm{C}$, to eliminate amplifiable contaminating genomic DNA. Complementary DNA was synthesized from $1 \mu \mathrm{g}$ of total RNA per sample with a 60 -min incubation at $42^{\circ} \mathrm{C}$, using the Moloney murine leukaemia virus reverse transcriptase (Invitrogen, Karlsruhe, Germany) and oligo-(dT) priming (Boehringer Mannheim). Amplification was carried out using gene-specific primers and Platinum-Taq polymerase (Invitrogen) in a Mastercycler Gradient thermocycler (Eppendorf, Hamburg, Germany). Reactions were performed in the presence of $0.5 \mu \mathrm{l} \mathrm{cDNA}$, with an initial incubation step at $95^{\circ} \mathrm{C}$ for $2 \mathrm{~min}$. Cycling conditions consisted of denaturation at $95^{\circ} \mathrm{C}$ for $30 \mathrm{sec}$, annealing at $60^{\circ} \mathrm{C}$ for $30 \mathrm{sec}$ and extension at $72^{\circ} \mathrm{C}$ for $30 \mathrm{sec}$ over a total of 30 cycles. The reaction was completed by another 10 -min incubation step at $72^{\circ} \mathrm{C}$. The specific sequences for sense and antisense primers are shown in Table I. The PCR products were subjected to electrophoresis in $1.5 \%$ agarose gel and visualized by ethidium bromide.

Drug treatment. Tumor cells were treated with valproic acid (VPA; Sigma, Munich, Germany) at a final concentration of $1 \mathrm{mM}$ for 3 or 5 days. Tumor cell proliferation, adhesion, $\alpha$ integrin coding mRNA and $\alpha$ integrin surface expression were then measured in VPA-treated cells. The results were compared to untreated controls. The viability of tumor cells in the presence of VPA was assessed by propidium iodide dsDNA-intercalation or quantitative fluorescence analysis of enzyme-catalyzed fluorescein-diacetate metabolism.

Statistical analysis. All experiments were performed 3-6 times. Statistical significance was investigated by the Wilcoxon-Mann-Whitney U-test. Differences were considered statistically significant at $\mathrm{p}<0.05$.

\section{Results}

VPA down-regulates tumor cell growth. Proliferation analysis revealed rapid cell growth of both HT-29 and DanG cells. HT-29 showed higher proliferative capacity than DanG, with doublings every $48 \mathrm{~h}$. Application of $1 \mathrm{mM}$ VPA resulted in a significant reduction in cell proliferation of both cell lines, compared to the controls (Fig. 1). The efficacy of the VPA therapy significantly depended on the drug exposure time, 
3 days
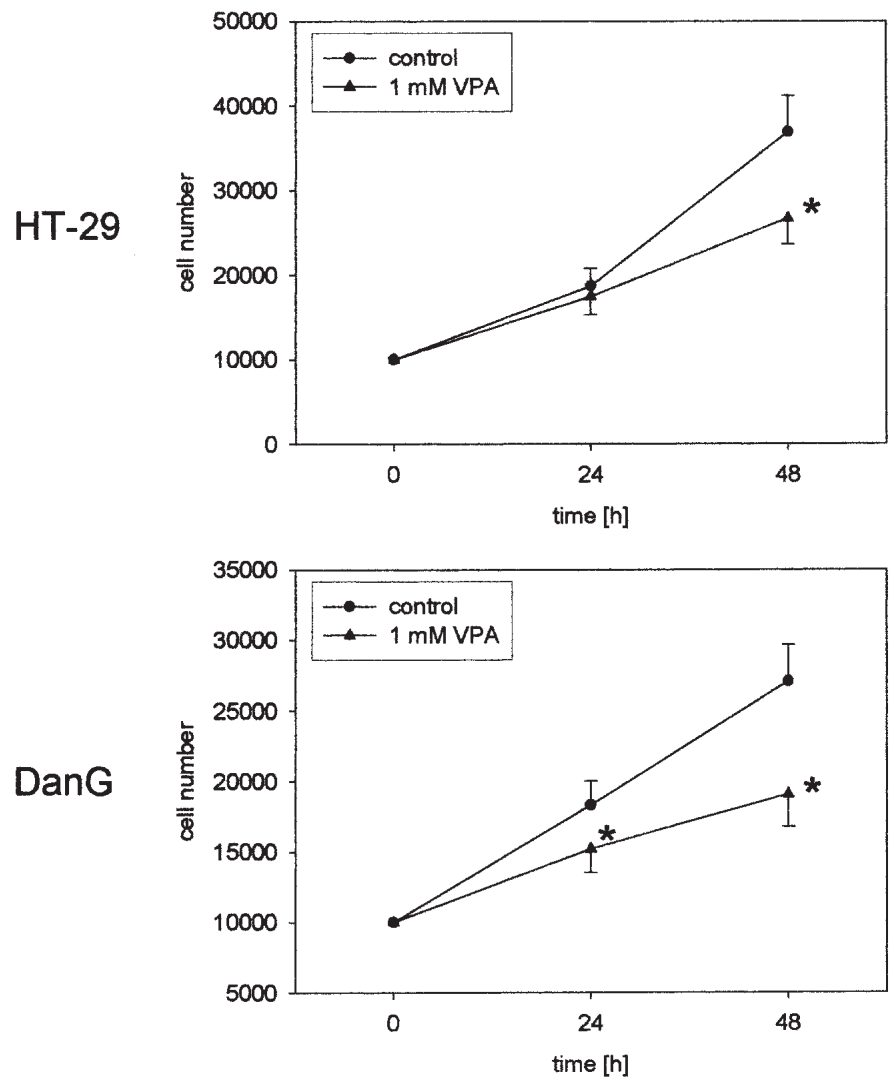

5 days
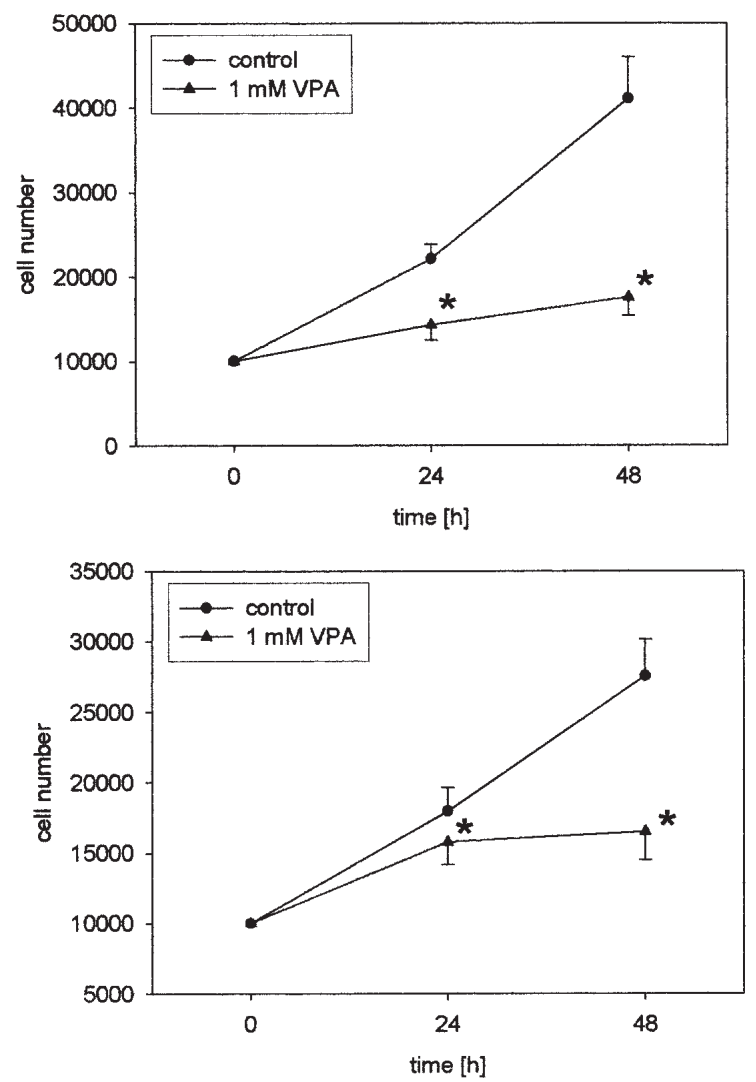

Figure 1. Effects of VPA on colon and pancreatic cancer proliferation. HT-29 or DanG cells were treated with 1 mM VPA for 3 or 5 days, or remained untreated (control). Cells were then seeded on 96-well culture plates, and cell proliferation was assessed using the 3-(4,5-dimethylthiazol-2-yl)-2,5diphenyltetrazolium bromide (MTT) dye reduction assay. Each data point depicts the mean value \pm SD of 3 wells. The figure shows a typical example from 6 independent experiments. "Significant difference compared to the controls.

since a 5-day VPA pre-treatment evoked a stronger response than a 3-day pre-treatment.

VPA alters tumor cell adhesion to HUVECs. Fig. 2 shows the adhesion kinetics of treated versus non-treated tumor cells. The initial attachment rate of control HT-29 cells was higher, and the plateau phase was reached much earlier than the initial attachment and saturation level of control DanG cells. However, independently from the different adhesion characteristics, VPA evoked a significant blockade of both HT-29 and DanG tumor cell adhesion to HUVECs, particularly when the compound was applied for 5 days. Colon HT-29 cells were more sensitive to VPA treatment than pancreatic DanG cells. The mean percentage in the reduction of HT-29 cell adhesion was $47.7 \pm 17.9 \%$ (2-h value) and $58.7 \pm 12.6 \%$ (4-h value) versus $32.5 \pm 6.6 \%$ (DanG cells, 2-h value) and 35.1 $\pm 10.2 \%$ (DanG, 4-h value).

Integrin a subtype surface expression. Fig. 3 depicts the integrin $\alpha$ subtype surface expression level for untreated HT-29 and DanG cells. The upper panel of the figure pertains to FITC-labelled antibodies; the lower panel to PE-labelled antibodies. The highest expression levels were detected with respect to $\alpha 3, \alpha 1, \alpha 2$ and $\alpha 6$ subtypes were expressed moderately in both cell lines, and $\alpha 4$ and $\alpha 5$ were just slightly elevated over the background.

VPA modulates the a integrin expression pattern. VPA induced distinct modifications of the $\alpha$ integrin subtypes (Fig. 4). However, the type and quantity of alterations depended on the VPA exposure time and the cell line used. $\alpha 1$ was drastically elevated in both HT-29 and DanG cells, particularly when tumor cells were exposed to this drug for 3 days. $\alpha 2$ was reduced in HT-29 but not in DanG cells after a 5-day VPA incubation compared to the controls. $\alpha 3$ was increased in HT-29 but decreased in DanG cells when VPA was applied for 3 days, whereas a 5-day VPA exposure evoked a significant receptor decrease in both cell lines. Both integrin $\alpha 4$ and $\alpha 5$ were enhanced in DanG but not in HT-29 cells by VPA. $\alpha 6$ was strongly diminished in HT-29 when VPA was added for 5 days, but was elevated in DanG cells after a 3-day VPA exposure.

Influence of VPA on integrin a mRNA. Modifications of the integrin $\alpha$ coding mRNA were analyzed next (Fig. 5). The experiments concentrated on $\alpha 1, \alpha 2, \alpha 3$ and $\alpha 6$ subtypes since no clear mRNA bands were observed with respect to integrin $\alpha 4$ and $\alpha 5$. mRNA levels of integrin $\alpha$ chains in DanG cells 
3 days

HT-29
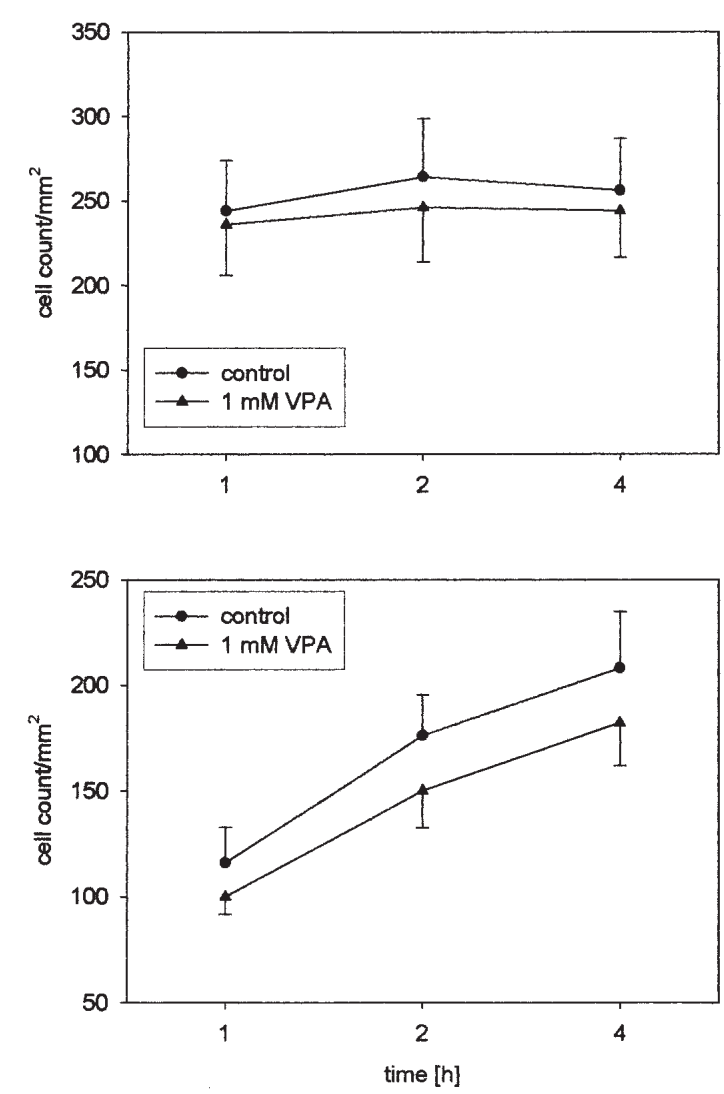

5 days
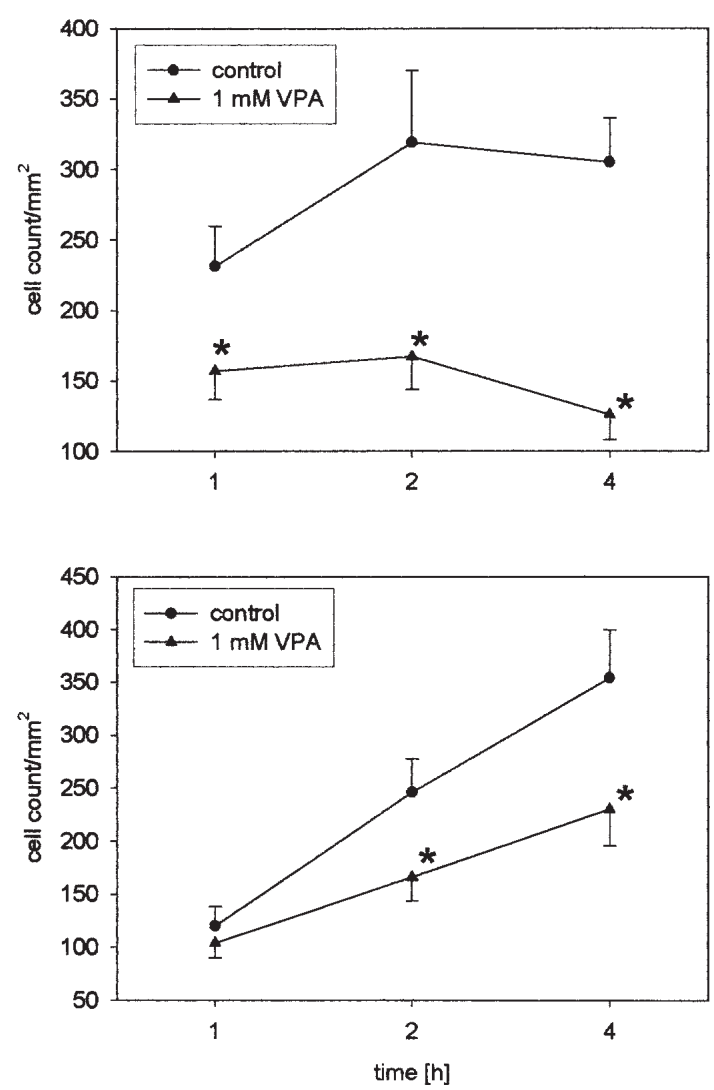

Figure 2. Adhesion of colon and pancreatic cancer cells to HUVECs was down-regulated by VPA. HT-29 or DanG cells were treated with 1 mM VPA for 3 or 5 days, and then added at a density of $0.5 \times 10^{6}$ cells/well to HUVEC monolayers for different time periods. Non-adherent tumor cells were washed off in each sample, and the remaining cells were fixed and counted in five different fields $\left(5 \times 0.25 \mathrm{~mm}^{2}\right)$ using a phase contrast microscope. Mean values were calculated from five counts. Mean adhesion capacity is depicted as counted cells $/ \mathrm{mm}^{2}$. One representative of six experiments is shown. ${ }^{*}$ Significant difference compared to controls.

did not change, independently of whether VPA was applied for 3 or for 5 days. In contrast, $\alpha 2$ and $\alpha 5$ mRNA levels were diminished in HT-29 cells, 3 and 5 days after VPA treatment, as compared to the controls. $\alpha 3 \mathrm{mRNA}$ was decreased 5 days after the addition of VPA. $\alpha 1 \mathrm{mRNA}$ was not detected in the HT-29 cells.

\section{Discussion}

VPA potently down-regulated the proliferation and adhesion capacity of colon and pancreatic tumor cells at a concentration well tolerated in epileptic patients.

Several studies indicate that VPA modulates the biology of diverse cancer types by suppressing tumor growth, metastasis and angiogenesis, and by inducing differentiation and apoptosis. Nevertheless, data on the effects of VPA on colon or pancreatic cancer are sparse. VPA has recently been shown to exert anti-fibrogenic effects on pancreatic stellate cells (PSC) and to strongly inhibit PSC proliferation (6). This finding is relevant, since pancreatic tumor growth is accelerated by PSC (7). Further studies point to the HDAC inhibitors TSA $(8,9)$, SAHA (10) and FK228 (11) which have exerted growth-inhibitory and pro-apoptotic effects in pancreatic cancer cell models.
Apoptotic processes and a proliferation blockade have also been observed in colon tumor cell lines (12) and in primary colon cancer isolates treated with VPA (13). VPA repressed the angiogenic factors VEGF and FGF at both the protein and mRNA levels (14), and decreased angiogenesis in colon tumor explants assessed by three-dimensional collagen matrix assays (15).

VPA significantly influenced both the growth and adhesion behaviour of human colon and pancreatic carcinoma cells. VPA administered for 5 days was more potent on HT-29 and DanG adhesion and proliferation than a 3-day incubation. Long-term application of VPA therefore seems necessary to delay tumor cell growth and block metastatic processes. In fact, prolonged VPA exposure was necessary to modify neuroectodermal tumor cells $(16,17)$, and Xia et al proposed that chronic administration of VPA is required to achieve therapeutic benefits for prostate carcinoma (18).

To analyze the mode of action of VPA, we concentrated on integrin adhesion receptors since they are crucially involved in tumor malignancy and dissemination, although their exact role is still controversial. $\beta 1$ integrin downregulation has been shown to enhance the binding of pancreatic cancer cells to extracellular matrix proteins (19), whereas further data demonstrate that loss of $\beta 1$-integrins 


\section{Integrin alpha subtype expression}

\section{IgG1-FITC}

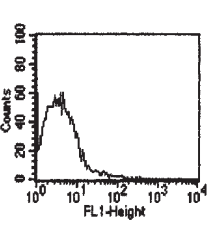

HT-29

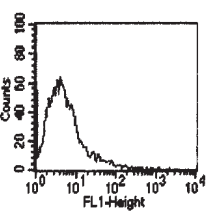

IgG1-PE
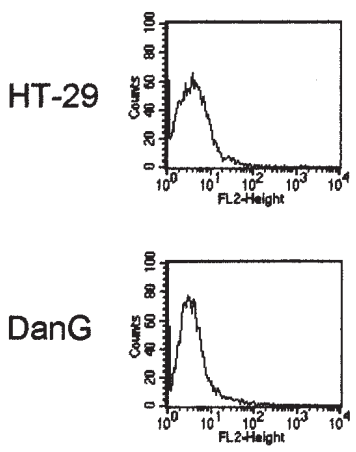

alpha2
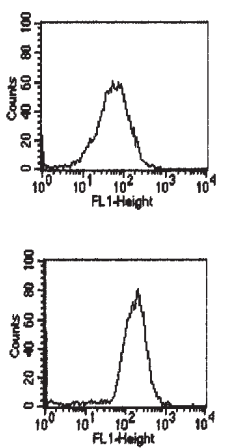

alpha1
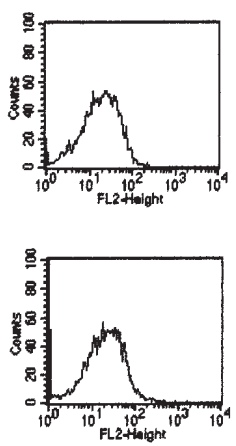

alpha4
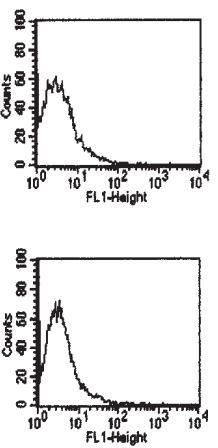

alpha3 alpha5
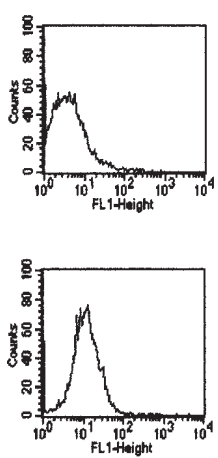

alpha6
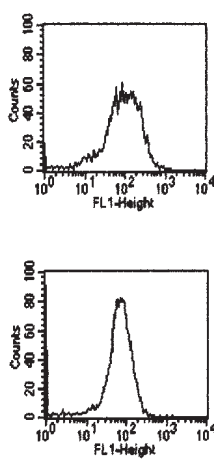
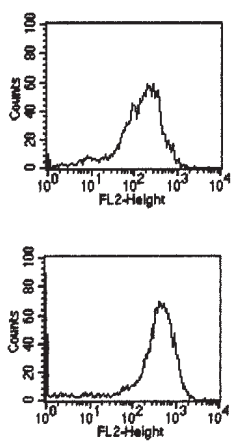

Figure 3. FACS analysis of B1 integrin surface expression on HT-29 and DanG cells. Cells were washed in blocking solution and then stained with specific monoclonal antibodies as listed in Materials and methods. A mouse IgG1-FITC was used as an isotype control for FITC-conjugated antibodies (upper panel). To evaluate background staining of PE-conjugated antibodies, goat anti-mouse IgG1-PE was used (lower panel). Fluorescence was analyzed using a FACScan flow cytometer, and a histogram plot was generated to show FITC/PE fluorescence.

causes tumor cell dissemination (20). With respect to colon cancer, the loss of integrin-mediated cell-matrix adhesion has been reported to contribute to high tumor cell motility (21). The relevance of this phenomenon is not clear. Novel findings suggest that integrin translocation from the cell surface into the cytoplasm may contribute to tumor metastasis. Winterwood et al concluded that integrin internalization is a key mechanism, necessary to control adhesion and migration dynamics of carcinoma cells, and, consequently, that high integrin surface expression impairs motile behaviour (22). According to this observation, VPA reduced the motility of murine fibrosarcoma L929 tumor cells, and the blocking of integrin B1-binding sites counteracted the effects of VPA (23). Nevertheless, our data did not provide a consistent picture of the mode of action of VPA. Although VPA induced a distinct elevation of $\alpha 1$ and $\alpha 3$ integrin subtypes after 3 days, $\alpha 2, \alpha 3$ and $\alpha 6$ integrins diminished after 5 days in HT-29 cells. Regarding pancreatic cancer cells, $\alpha 1$ and $\alpha 6$ were enhanced after 3 days, $\alpha 4$ and $\alpha 5$ were up-regulated after 5 days, whereas $\alpha 3$ was drastically reduced by VPA. VPA, therefore, triggers both receptor enhancement as well as receptor reduction.

Tumor development is caused by dysregulation of the 'physiological' integrin $\beta 1$ balance towards a pathological expression pattern, which includes both enhanced expression as well as loss of specific $\beta 1$ subtypes (24). Presumably, VPA reprograms pancreatic and colon tumor cells and reestablishes the 'physiologic' integrin expression pattern as was previously demonstrated in a renal cell carcinoma model (24). According to this hypothesis, treatment of hepatocellular carcinoma cells with the HDAC inhibitor TSA led to reduced migration activities, accompanied by simultaneous up- and down-regulation of particular integrin subtypes (25).

Nevertheless, although VPA acted on both HT-29 and DanG cells, adhesion was blocked to a different extent, implying tumor-specific effects of VPA. Duenas-Gonzalez and coworkers have also assumed that the therapeutic efficacy of VPA depends on the cancer type (26). The molecular background for the unequal adhesion manipulation has not yet been evaluated. However, VPA diminished integrin coding mRNA in HT-29 but not in DanG cells. Therefore, selective prevention of integrin de novo synthesis might (at least in part) account for the different biological responses observed between colon and pancreatic tumor cells. Since VPA modified the integrin surface profile on both cell lines in a disparate manner, quantitative alterations of membranous integrin level may (additionally) determine the anti-tumor potential of VPA. 
alpha1

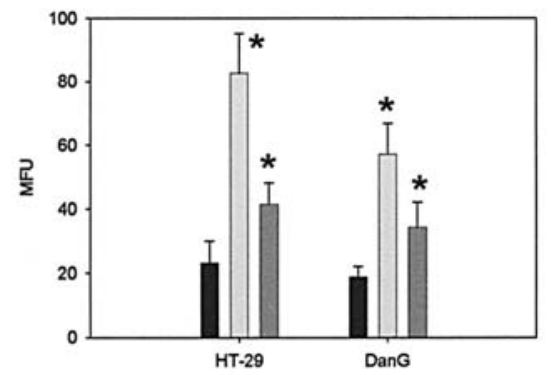

alpha4

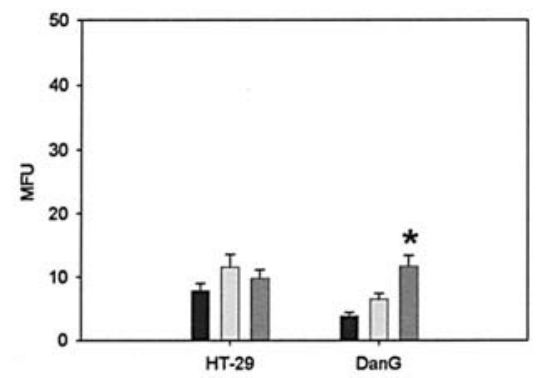

alpha2

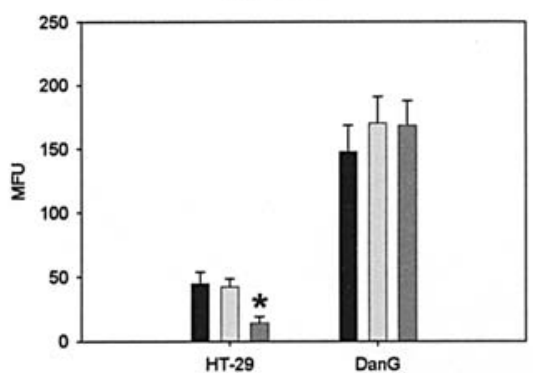

alpha5

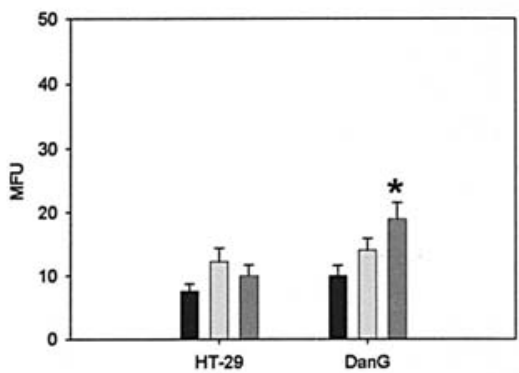

alpha3

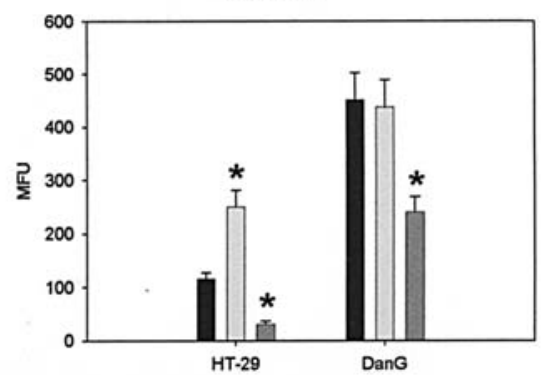

alpha6

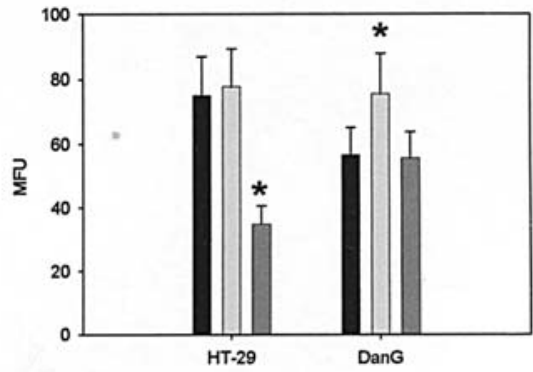

Figure 4. VPA modifies 31 integrin surface expression. HT-29 or DanG cells were treated with $1 \mathrm{mM}$ VPA for 3 or 5 days, or remained untreated (control). Tumor cells were washed in blocking solution and then stained with specific monoclonal antibodies as listed in Materials and methods. A mouse IgG1-FITC was used as an isotype control for FITC-conjugated antibodies. To evaluate the background staining of PE-conjugated antibodies, goat anti-mouse IgG1-PE was used. Fluorescence was analyzed using a FACScan flow cytometer. The y-axis depicts the mean fluorescence units (MFU) taken from one representative experiment. *Significant difference to controls.

HT-29

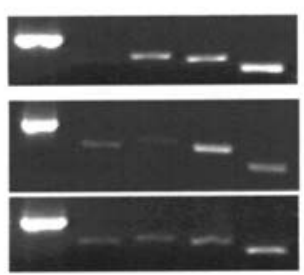

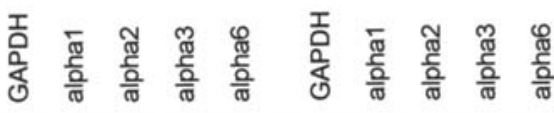

Figure 5. Semiquantitative RT-PCR analysis carried out on HT-29 and DanG tumor cells. Cells were treated with $1 \mathrm{mM}$ VPA for 3 or 5 days, or remained untreated (control). The figure demonstrates analysis of mRNA coding for $\alpha 1, \alpha 2, \alpha 3$ or $\alpha 6$ integrins. RNA was extracted, reversetranscribed and submitted to semi-quantitative reverse transcription-PCR using gene-specific primers as described in Materials and methods. The internal control for the RT-PCR reaction was performed by running parallel reaction mixtures with the housekeeping gene GAPDH. The figure shows one representative from three separate experiments.

Comparative analysis of pancreatic, colon and prostate carcinoma cell lines has revealed that $\beta 1$ integrins are not involved in tumor cell adhesion in the same manner (27), which indicates that even similar changes in a particular integrin by VPA may not evoke similar responses in different cell types. This means that $\alpha 1$ integrin, which was up-regulated similarly by VPA in HT-29 and DanG cells, might have higher relevance for colon cancer than for pancreatic cancer cell adhesion. Consequently, adhesion could be expected to be blocked to a higher extent in HT-29 than in DanG cells. Still, this hypothesis is speculative and must be supported by experimental findings.

In summary, VPA potently diminished the proliferation and adhesion capacity of colon and pancreatic tumor cell lines. VPA may shift the integrin $\beta 1$ subunit balance from a 'pathological' towards a 'physiological' expression pattern, leading to reduced tumor growth and invasion. Further study is necessary to elucidated the molecular background of the post-transcriptional modifications associated with VPA in order to exploit the potential of this agent in the treatment of colon and pancreatic cancer.

\section{Acknowledgements}

We would like to thank Karen Nelson for critically reading the manuscript. This work was supported by the 'Horst Müggenburg-Stiftung', 'Jung-Stiftung', 'Ebert-Stiftung' and 'Held-Hecker-Stiftung'. 


\section{References}

1. Cinatl J Jr, Cinatl J, Scholz M, Driever PH, Henrich D, Kabickova H, Vogel JU, Doerr HW and Kornhuber B: Antitumor activity of sodium valproate in cultures of human neuroblastoma cells. Anticancer Drugs 7: 766-773, 1996.

2. Blaheta RA, Michaelis M, Driever PH and Cinatl J Jr: Evolving anticancer drug valproic acid: insights into the mechanism and clinical studies. Med Res Rev 25: 383-397, 2005.

3. Munster P, Marchion D, Bicaku E, Schmitt M, Lee JH, DeConti R, Simon G, Fishman M, Minton S, Garrett C, Chiappori A, Lush R, Sullivan D and Daud A: Phase I trial of histone deacetylase inhibition by valproic acid followed by the topoisomerase II inhibitor epirubicin in advanced solid tumors: a clinical and translational study. J Clin Oncol 25: 1979-1985, 2007.

4. Atmaca A, Al-Batran SE, Maurer A, Neumann A, Heinzel T, Hentsch B, Schwarz SE, Hovelmann S, Gottlicher M, Knuth A and Jager E: Valproic acid (VPA) in patients with refractory advanced cancer: a dose escalating phase I clinical trial. Br J Cancer 97: 177-182, 2007.

5. Guo W and Giancotti FG: Integrin signalling during tumour progression. Nat Rev Mol Cell Biol 5: 816-826, 2004.

6. Bülow R, Fitzner B, Sparmann G, Emmrich J, Liebe S and Jaster R: Antifibrogenic effects of histone deacetylase inhibitors on pancreatic stellate cells. Biochem Pharmacol 74: 1747-1757, 2007.

7. Bachem MG, Schünemann M, Ramadani M, Siech M, Beger H, Buck A, Zhou S, Schmid-Kotsas A and Adler G: Pancreatic carcinoma cells induce fibrosis by stimulating proliferation and matrix synthesis of stellate cells. Gastroenterology 128: 907-921, 2005.

8. Donadelli M, Costanzo C, Beghelli S, Scupoli MT, Dandrea M, Bonora A, Piacentini P, Budillon A, Caraglia M, Scarpa A and Palmieri M: Synergistic inhibition of pancreatic adenocarcinoma cell growth by trichostatin $\mathrm{A}$ and gemcitabine. Biochim Biophys Acta 1773: 1095-1106, 2007.

9. Bai J, Demirjian A, Sui J, Marasco W and Callery MP: Histone deacetylase inhibitor trichostatin A and proteasome inhibitor PS-341 synergistically induce apoptosis in pancreatic cancer cells. Biochem Biophys Res Commun 348: 1245-1253, 2006.

10. Kumagai T, Wakimoto N, Yin D, Gery S, Kawamata N, Takai N, Komatsu N, Chumakov A, Imai Y and Koeffler HP: Histone deacetylase inhibitor, suberoylanilide hydroxamic acid (Vorinostat, SAHA) profoundly inhibits the growth of human pancreatic cancer cells. Int J Cancer 121: 656-665, 2007.

11. Sato N, Ohta T, Kitagawa H, Kayahara M, Ninomiya I, Fushida S, Fujimura T, Nishimura G, Shimizu K and Miwa K: FR901228, a novel histone deacetylase inhibitor, induces cell cycle arrest and subsequent apoptosis in refractory human pancreatic cancer cells. Int J Oncol 24: 679-685, 2004.

12. Huang $X$ and Guo B: Adenomatous polyposis coli determines sensitivity to histone deacetylase inhibitor-induced apoptosis in colon cancer cells. Cancer Res 66: 9245-9251, 2006.

13. Friedmann I, Atmaca A, Chow KU, Jäger E and Weidmann E: Synergistic effects of valproic acid and mitomycin $\mathrm{C}$ in adenocarcinoma cell lines and fresh tumor cells of patients with colon cancer. J Chemother 18: 415-420, 2006.

14. Zgouras D, Becker U, Loitsch S and Stein J: Modulation of angiogenesis-related protein synthesis by valproic acid. Biochem Biophys Res Commun 316: 693-697, 2004.
15. Isenberg JS, Jia Y, Field L, Ridnour LA, Sparatore A, Del Soldato P, Sowers AL, Yeh GC, Moody TW, Wink DA, Ramchandran R and Roberts DD: Modulation of angiogenesis by dithiolethione-modified NSAIDs and valproic acid. Br J Pharmacol 151: 63-72, 2007.

16. Blaheta RA, Michaelis M, Natsheh I, Hasenberg C, Weich E, Relja B, Jonas D, Doerr HW and Cinatl J Jr: Valproic acid inhibits adhesion of vincristine- and cisplatin-resistant neuroblastoma tumour cells to endothelium. Br J Cancer 96: 1699-1706, 2007.

17. Beecken WD, Engl T, Ogbomo H, Relja B, Cinatl J, Bereiter-Hahn J, Oppermann E, Jonas D and Blaheta RA: Valproic acid modulates NCAM polysialylation and polysialyltransferase mRNA expression in human tumor cells. Int Immunopharmacol 5: 757-769, 2005.

18. Xia Q, Sung J, Chowdhury W, Chen CL, Hoti N, Shabbeer S, Carducci $\mathrm{M}$ and Rodriguez R: Chronic administration of valproic acid inhibits prostate cancer cell growth in vitro and in vivo. Cancer Res 66: 7237-7244, 2006.

19. Grzesiak JJ and Bouvet M: Activation of the alpha(2)beta(1) integrin-mediated malignant phenotype on type I collagen in pancreatic cancer cells by shifts in the concentrations of extracellular $\mathrm{Mg}(2+)$ and $\mathrm{Ca}(2+)$. Int J Cancer 122: 2199-2209, 2008.

20. Kren A, Baeriswyl V, Lehembre F, Wunderlin C, Strittmatter K, Antoniadis H, Fässler R, Cavallaro U and Christofori G: Increased tumor cell dissemination and cellular senescence in the absence of beta1-integrin function. EMBO J 26: 2832-2842, 2007.

21. Shi X, Ma YQ, Tu Y, Chen K, Wu S, Fukuda K, Qin J, Plow EF and $\mathrm{Wu} \mathrm{C}$ : The MIG-2/integrin interaction strengthens cellmatrix adhesion and modulates cell motility. J Biol Chem 282: 20455-20466, 2007.

22. Winterwood NE, Varzavand A, Meland MN, Ashman LK and Stipp CS: A critical role for tetraspanin CD151 in alpha3beta1 and alpha6beta4 integrin-dependent tumor cell functions on laminin-5. Mol Biol Cell 17: 2707-2721, 2006.

23. Walmod PS, Skladchikova G, Kawa A, Berezin V and Bock E: Antiepileptic teratogen valproic acid (VPA) modulates organisation and dynamics of the actin cytoskeleton. Cell Motil Cytoskeleton 42: 241-255, 1999.

24. Oertl A, Relja B, Makarevic J, Weich E, Höfler S, Jones J, Jonas D, Bratzke H, Baer PC and Blaheta RA: Altered expression of betal integrins in renal carcinoma cell lines exposed to the differentiation inducer valproic acid. Int J Mol Med 18: 347-354, 2006.

25. Lin KT, Yeh SH, Chen DS, Chen PJ and Jou YS: Epigenetic activation of alpha4, beta2 and beta6 integrins involved in cell migration in trichostatin A-treated Hep3B cells. J Biomed Sci 12: 803-813, 2005.

26. Duenas-Gonzalez A, Candelaria M, Perez-Plascencia C, Perez-Cardenas E, de la Cruz-Hernandez E and Herrera LA: Valproic acid as epigenetic cancer drug: Preclinical, clinical and transcriptional effects on solid tumors. Cancer Treat Rev 2008 Jan. 15 (Epub ahead of print).

27. Klein G, Langegger M, Timpl R and Ekblom P: Role of laminin A chain in the development of epithelial cell polarity. Cell 55: 331-341, 1988. 